Research Article

\title{
Preparation and Characterization of Lauric-Myristic Acid/Expanded Graphite as Composite Phase Change Energy Storage Material
}

\author{
Dongyi Zhou $\mathbb{D}^{1,2,3}$ Jiawei Yuan, ${ }^{1,3}$ Xianghua Xiao, ${ }^{1,3}$ and Yicai Liu $\mathbb{B D}^{2}$ \\ ${ }^{1}$ School of Mechanical and Energy Engineering, Shaoyang University, Shaoyang 422000, China \\ ${ }^{2}$ School of Energy Science and Engineering, Central South University, Changsha 410083, China \\ ${ }^{3}$ Key Laboratory of Hunan Province for Efficient Power System and Intelligent Manufacturing, Shaoyang University, \\ Shaoyang 422000, China
}

Correspondence should be addressed to Dongyi Zhou; zhoudongyi2005@163.com and Yicai Liu; lyc0300@163.com

Received 12 April 2021; Revised 12 May 2021; Accepted 28 May 2021; Published 17 June 2021

Academic Editor: Sami-Ullah Rather

Copyright (C) 2021 Dongyi Zhou et al. This is an open access article distributed under the Creative Commons Attribution License, which permits unrestricted use, distribution, and reproduction in any medium, provided the original work is properly cited.

Lauric acid (LA) and myristic acid (MA) were used to prepare a binary eutectic mixture. The expanded graphite (EG) was used as the carrier, and the lauric-myristic acid/expanded graphite (LA-MA/EG) composite phase change material was prepared by physical adsorption method. The microstructure, chemical structure, and thermal properties of LA-MA/EG were characterized by scanning electron microscopy (SEM), differential scanning calorimeter (DSC), Fourier transform infrared spectroscopy (FTIR), and thermal conductivity measurement. The experimental results have shown that the maximum mass ratio of the binary eutectic mixture in the LA-MA/EG composite phase change energy-storing material was $92.2 \%$, and there was physical mixing and has no chemical reaction between LA-MA and EG. The fusion point temperature of LA-MA/EG was $33.4^{\circ} \mathrm{C}$, the solidification point temperature was $33.8^{\circ} \mathrm{C}$, and the latent heat was $171.1 \mathrm{~J} / \mathrm{g}$, which was suitable for building energy storage field. After several thermal cycles, the change of the fusion point and potential heat of the composite phase change materials were very small, and it still has good energy storage performance.

\section{Introduction}

Because of the growing energy shortage in today's society, it is particularly important to improve the effective utilization of traditional energy gradually; the development and application of new energy resources such as solar energy are also significant. Thermal energy storage (TES) has become a wide development prospect technology in order to improve the utilization rate of renewable energy [1-3]. In general, according to the different heat storage mechanisms, TES technology is divided into sensible heat energy storage technology, latent heat energy storage technology, and chemical reaction energy storage technology [4]. The chemical reaction energy storage technology can release heat energy through the endothermic and exothermic processes of chemical reactions [5], and due to the high cost of equipment, complex operation process, and the risk of chemical hazards, it is not applicable to the field of building energy conservation. Sensible heat storage technology can store and release heat energy by changing the temperature of thermal insulation materials [6], and the technology was relatively mature but the storage density was low. Latent heat energy storage technology utilizes the characteristics of heat energy release and absorption of PCMs during the transition between solid phase and liquid phase $[7,8]$, to achieve the goal of energy storage, temperature control, and energy recovery and reuse and balance the contradiction between energy supply and demand [9]. It has the advantages of high potential heat of phase transition, high energy storage density, and stable temperature output and has a broad application prospect in many fields such as building energy conservation $[10,11]$, solar energy utilization [12-14], recycling and utilization of industrial 
TABLE 1: Heat performances of some phase change materials (PCMs) and composite phase change materials (CPCMs). CA: capric acid; LA: lauric acid; MA: myristic acid; PA: palmitic acid; SA: stearic acid; EG: expanded graphite.

\begin{tabular}{|c|c|c|c|c|c|}
\hline \multirow{2}{*}{ PCMs/CPCMs } & \multicolumn{2}{|c|}{ Melting } & \multicolumn{2}{|c|}{ Freezing } & \multirow{2}{*}{ Reference } \\
\hline & Temperature $\left({ }^{\circ} \mathrm{C}\right)$ & Latent heat $(\mathrm{J} / \mathrm{g})$ & Temperature $\left({ }^{\circ} \mathrm{C}\right)$ & Latent heat $(\mathrm{J} / \mathrm{g})$ & \\
\hline PA-SA & 54.81 & 187.0 & 54.06 & 179.7 & \multirow{2}{*}[39]{} \\
\hline PA-SA/EG & 55.18 & 176.2 & 54.91 & 175.6 & \\
\hline MA-PA-SA & 41.72 & 163.5 & 42.38 & 159.8 & \multirow{2}{*}[40]{} \\
\hline MA-PA-SA/EG & 41.64 & 153.5 & 42.99 & 151.4 & \\
\hline CA-MA-PA & 18.98 & 135.6 & 17.26 & 131.9 & \multirow{2}{*}[41]{} \\
\hline CA-MA-PA/EG & 18.61 & 128.2 & 16.58 & 124.5 & \\
\hline LA-SA & 35.54 & 159.9 & 34.36 & I & \multirow{2}{*}[42]{} \\
\hline LA-SA/EG & 35.69 & 143.4 & 34.28 & I & \\
\hline LA-MA & 33.90 & 176.9 & 32.6 & 154.1 & \multirow{2}{*}{ This study } \\
\hline LA-MA/EG & 33.4 & 171.1 & 33.8 & 152.3 & \\
\hline
\end{tabular}

exhaust heat [15], food storage [16], the balance of the electric power, and military infrared camouflage, getting more and more extensive attention.

Phase change materials (PCMs) can supply a large heat capacity with a limited range of temperatures, and the phase change process was isothermal. Phase change materials used in construction must meet its phase transition temperature were within the scope of the indoor temperature, latent heat of large, stable chemical performance, not leak and metamorphism, etc. [17, 18]. According to the phase state, phase change materials can be divided into solid-solid phase change materials [19], solid-liquid phase change material [20], solid-gas phase change material, and liquid-gas phase change material. According to their chemical composition, they can be divided into organic phase change materials [21] and inorganic phase change materials [22]; organic phase change materials are divided into the paraffin [23] and nonparaffin; subdivided, nonparaffin phase change materials include alcohols [24], lipids, diols, and fatty acids, and different kinds of phase change materials have certain limitations in their application. As a kind of common organic PCM, fatty acids are cheap and easy to obtain. Due to their high latent heat of phase change, stable performance $[25,26]$, and different melting temperatures, fatty acids can adapt to different climatic conditions and be widely used in the research and application of building energy conservation.

Although fatty acids have many advantages, they still have the negative characteristics of poor thermal conductivity and easy leakage of pure phase change materials [27]. To resolve this problem, high thermal conductivity materials can be added into fatty acid PCM to prepare composite phase change materials. Not only can composite phase change materials be improved in terms of thermal conductivity, but they can also be made into stable PCMs which are not as likely to leak. The commonly used base materials for preparing shaped phase change materials include expanded graphite [28, 29], expanded perlite [30], diatomite [31], and activated carbon. The commonly used preparation methods of composite phase change materials include the microcapsule method [32], sol-gel method [33], solution-melt infiltration method, and physical adsorption method [34].
Zhang et al. studied a composite phase change material (CPCM) of capric acid, palmitic acid, and stearic acid ternary eutectic mixture/expanded graphite (CA-PA-SA/EG) used for low-temperature heat storage. CA-PA-SA/EG composite phase change material was a kind of promising energy storage material at low temperature, and the melting and freezing temperatures were $21.33^{\circ} \mathrm{C}$ and $19.01^{\circ} \mathrm{C}$, severally. And the latent heat of CA-PA-SA/EG was $131.7 \mathrm{~J} / \mathrm{g}$ and $127.2 \mathrm{~J} / \mathrm{g}$, respectively. CA-PA-SA/EG composite PCMs were dry and easy to be pressed, and thermal conductivity was much higher than the ternary eutectic mixture of CA-PA-SA. The thermal performance test has shown that with the increase of thermal conductivity of CA-PA-SA, the melting/cooling time was obviously shortened. After 500 times thermal cycling test, the result indicated that CA-PA-SA/EG composite phase change material has good thermal reliability [35]. Many studies have shown that adding the expanded graphite can not only prevent the leakage occurred in the molten state of PCMs but also extremely strengthen the thermoconductivity of CPCMs and enhance the thermal performance [36-38]. The thermal properties of some PCM and composite PCM were shown in Table 1.

LA and MA as PCMs applied in the fields of lowtemperature thermal storage, such as building heating/cooling and indoor temperature controlling, represent higher phase change temperatures. In this paper, the phase transition temperature and potential thermal of the prepared LA-MA/EG were $33.9^{\circ} \mathrm{C}$ and $176.9 \mathrm{~J} / \mathrm{g}$, severally, and it can be extensively used in low-temperature energy storage areas. The LA-MA/EG composite PCM was prepared by the physical adsorption method. The scanning electron microscopy (SEM) measurement was used for the LA-MA/EG microstructure; Fourier transform infrared spectroscopy (FTIR) tests the material structure and determines the combination between LA-MA binary eutectic mixture and EG; the CPCM phase transition point and phase change latent heat were determined by differential scanning calorimeter (DSC); the CPCM thermal stability was determined by thermogravimetric analysis (TGA); the change of the change phase point and latent heat of CPCMs after multiple phase transformation were determined by thermal cycle test; the thermal storage 


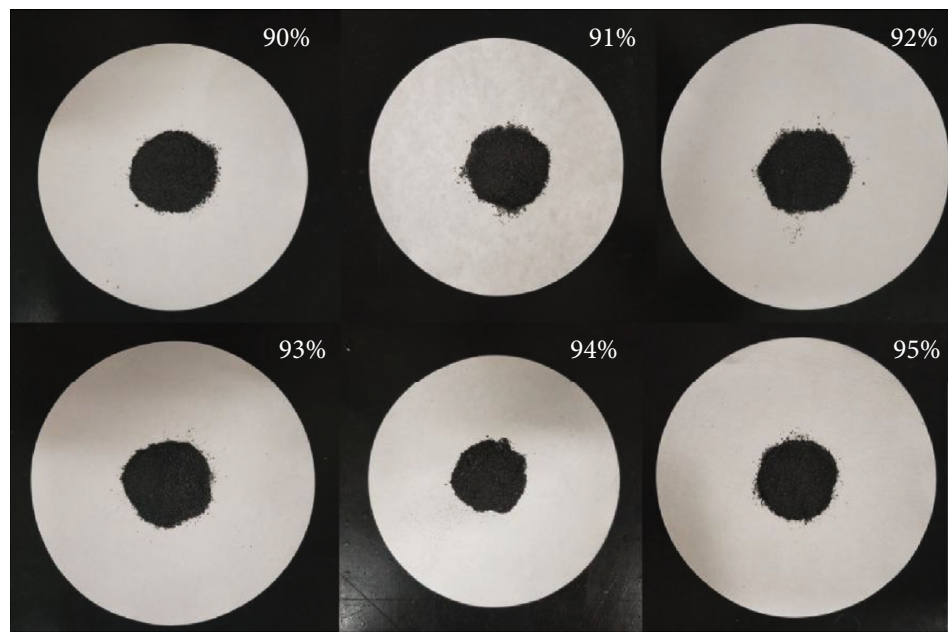

(a)

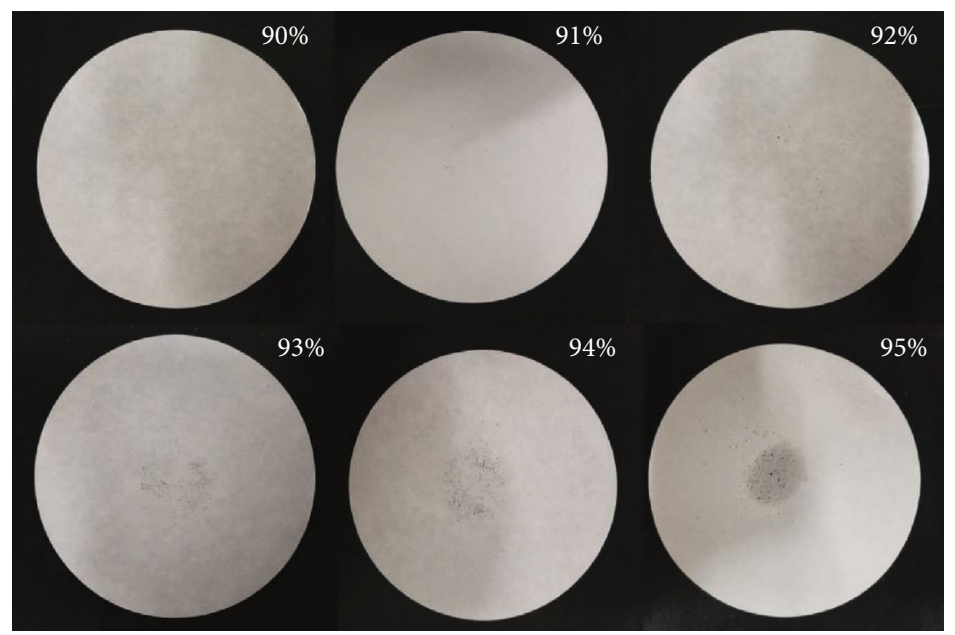

(b)

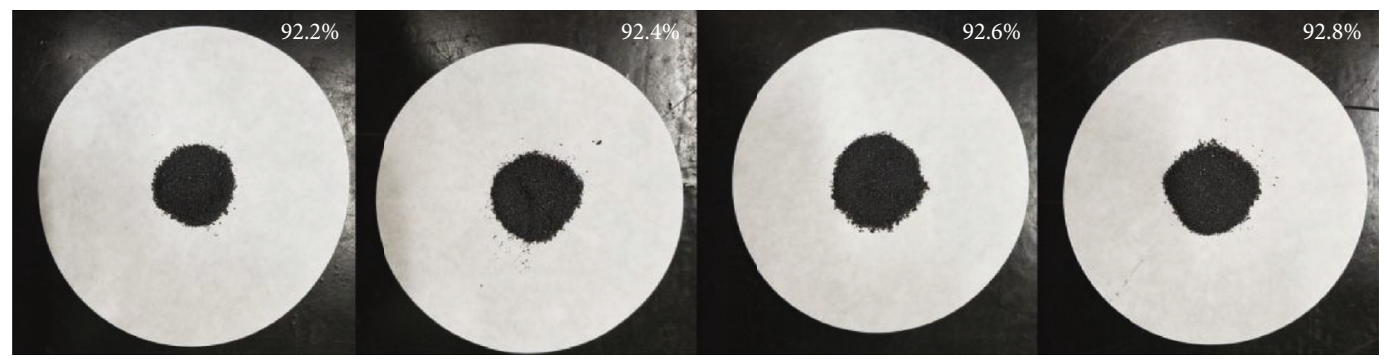

(c)

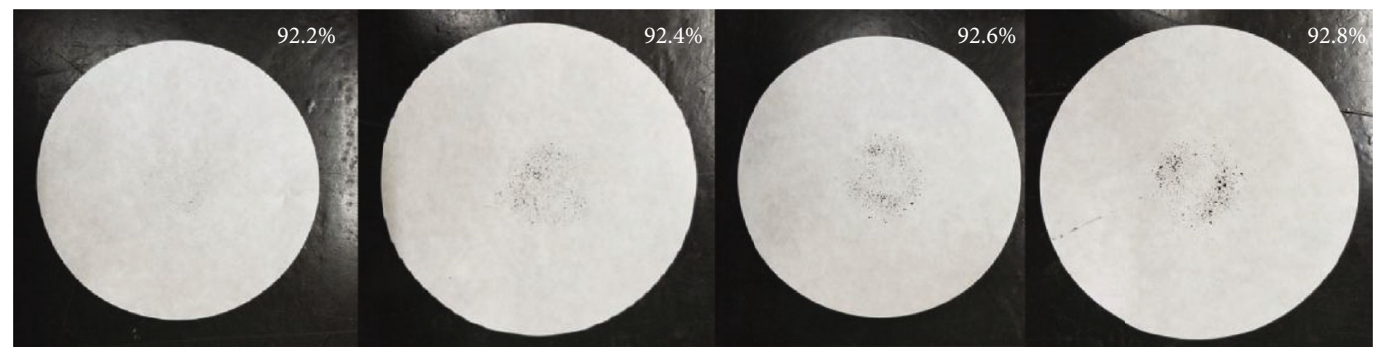

(d)

FiguRE 1: The LA-MA/EG CPCM samples before and after heat treatment. (a) The first set of specimens after heat treatment; (b) the first set of filter papers with specimens brushed off after thermal treatment; (c) the second set of specimens after heat treatment; (d) the leakage of the second set of filter papers with specimens brushed off after thermal treatment. 
and release capacity of CPCM was tested by heat storage and release experiment. Finally, the coefficient of heat conductivity of CPCM was measured by the thermal flow method.

\section{Experiments}

2.1. Materials. Lauric acid (LA, $\mathrm{C}_{12} \mathrm{H}_{24} \mathrm{O}_{2}$, analytical pure) was purchased from Shanghai Eppie Chemical Reagent Co., Ltd.; myristic acid (MA, $\mathrm{C}_{14} \mathrm{H}_{28} \mathrm{O}_{2}$, the $98 \%$ pure) was purchased from Shanghai Zhanyun Chemical Co., Ltd. Expansible graphite (particle size 80 mesh, expansion rate $350 \mathrm{~mL} / \mathrm{g}$, carbon content $99 \%$, and density $1.1 \mathrm{~g} / \mathrm{cm}^{3}$ ) was purchased from Qingdao Forest Graphite Products Co., Ltd., China.

2.2. LA-MA/EG CPCM Preparation. Take different content of LA and MA into the beakers, respectively, and heat them in a water bath with the temperature at $60^{\circ} \mathrm{C}$. After the fatty acids were fully dissolved, use the constant temperature magnetic stirrer to fully blend LA-MA, with a rotating speed of $500 \mathrm{r}$ for $30 \mathrm{~min}$, and then cool the mixture to room temperature.

Put an amount of expandable graphite into the beaker, seal the beaker with the thin film, and dry in a vacuum drying oven. Then, the expandable graphite after drying is heated at high temperature in a Muffle furnace. The expansion temperature is set as $900^{\circ} \mathrm{C}$, and the expansion time is $30-50 \mathrm{~s}$; finally, the expandable graphite can be obtained.

The eutectic mixture of LA-MA and EG was placed in the same beaker and stirred evenly with a glass rod. The thin film sealed beaker was used; then, the eutectic mixture was placed into a vacuum drying oven with temperature $50^{\circ} \mathrm{C}$ for $48 \mathrm{~h}$ and stirred evenly every $2 \mathrm{~h}$, to ensure that the PCM was uniform adsorption in the pores of EG. After cooling the sample to room temperature, the LA-MA/EG composite PCM was obtained.

2.3. Characterization. The differential scanning calorimeter (DSC; DSC instrument, STA2500, Germany) was used to measure the LA-MA/EG composite PC, and the phase transition temperature and phase change potential heat of LAMA/EG before and after the thermal cycle. Under a nitrogen atmosphere of $0.5 \mathrm{bar}$, the samples with a mass of $5-10 \mathrm{mg}$ were encapsulated in an aluminum crucible, the temperature range was set to $0-100^{\circ} \mathrm{C}$, and the temperature and the heat measurement accuracy was $\pm 2.0 \%$. In order to remove the sample thermal history, ignore the first heating cycle. The heating and cooling ratio was set to $10^{\circ} \mathrm{C} / \mathrm{min}$. After the test, a temperature-heat flow curve of the samples can be received. The phase transition temperature and phase transformation potential heat of the samples were obtained by the DSC analysis software.

The FTIR (FTIR instrument, Thermo Scientific Nicolet iS5, USA) was used to analyze the chemical structure of the LA-MA/EG composite PCM. Turn on the FTIR under the condition of suitable indoor temperature and stable voltage. After the background collection and testing, the LA-MA binary eutectic mixture and the LA-MA/EG composite PCM samples were put into the samples for testing, respec-

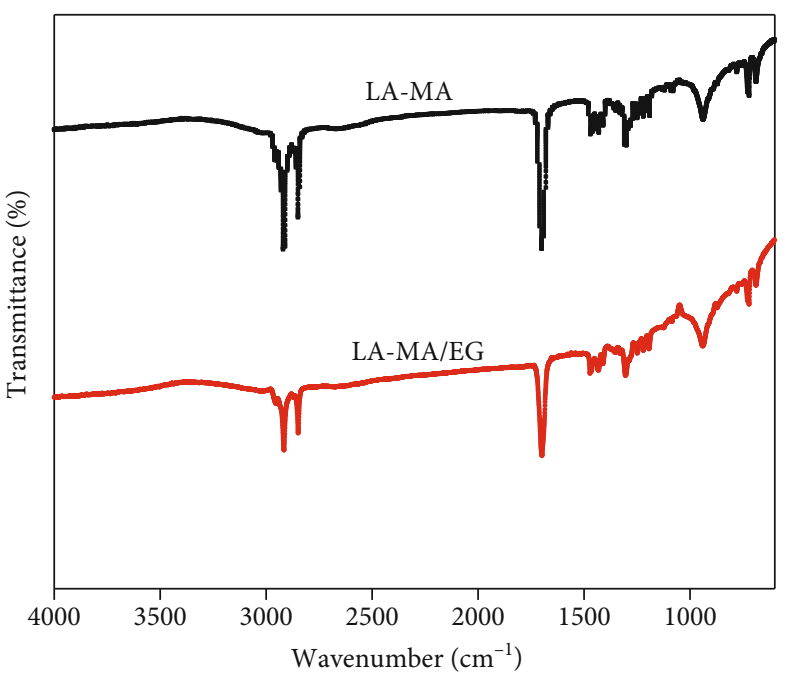

FIGURE 2: FTIR spectra of LA-MA and LA-MA/EG CPCMs.

tively, with a testing resolution of $4 \mathrm{~cm}^{-1}$ and a frequency of $4000-400 \mathrm{~cm}^{-1}$. Samples were scanned 16 times.

Using the scanning electron microscope (SEM, Phenom LE, Phenom-World, Eindhoven, the Netherlands) to observe the LA-MA/EG microstructure, take a small amount of sample placed on the thermal conductive adhesive tape and put into SEM, within the range between 2000x and 6000x, and shot several samples. The LA-MA/EG composite PCMs for the thermal cycle were carried on, after several thermal cycles, repeated to test the thermal properties of the composite phase change materials by DSC. Heat storage and release experiments of LA-MA binary eutectic mixture and LA$\mathrm{MA} / \mathrm{EG}$ were carried out with the temperature range between 0 and $50^{\circ} \mathrm{C}$, and the multiple intelligent temperature detector (YTJ-1638, Yuyao Yitai Instrument Factory, China) was used to record the temperature variation of the specimen during the whole cycle of thermal storage and release, and the data were recorded every $10 \mathrm{~s}$.

The thermogravimetric analysis technique (TGA, TG 209F3, NETZSCH, Germany) was used to analyze the heat durability and stability of PCMs and CPCMs [43]. Under the nitrogen atmosphere, the weightlessness temperature and weightlessness range of the samples were tested from the room temperature to $500^{\circ} \mathrm{C}$ at a heating rate of $10^{\circ} \mathrm{C} / \mathrm{min}$. Finally, the temperature-mass change curve of the samples was obtained by using the analysis software. A thermoconductivity analyzer (DRL-III, Xiangtan Xiangxi Instrument Co., LTD., China) was used to measure the thermoconductivity of PCMs with an accuracy of $\pm 3 \%$.

\section{Results and Discussion}

3.1. Maximum Mass Ratio of LA-MA in the LA-MA/EG Composite PCMs. Six groups of LA-MA/EG composite PCMs were prepared with sample weight of $5 \mathrm{~g}$ and different content of LA-MA (from 90\% to 95\%), respectively, with uniform distribution in the filter paper center diameter of $30 \mathrm{~mm}$ test area. Heat the samples in the vacuum drying oven at $50^{\circ} \mathrm{C}$ for $30 \mathrm{~min}$, cool to the room temperature and then 


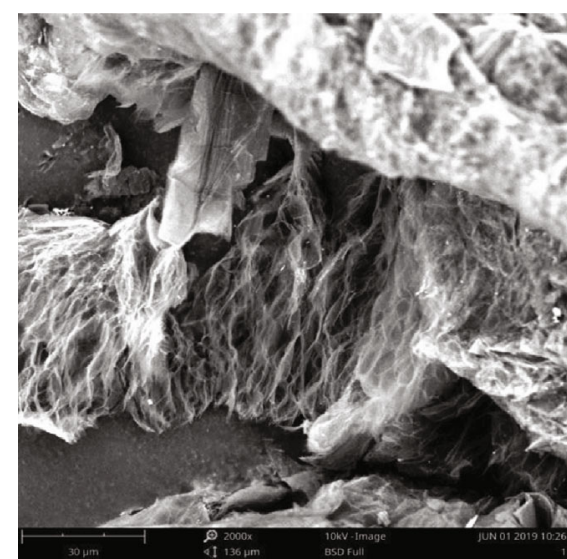

(a)

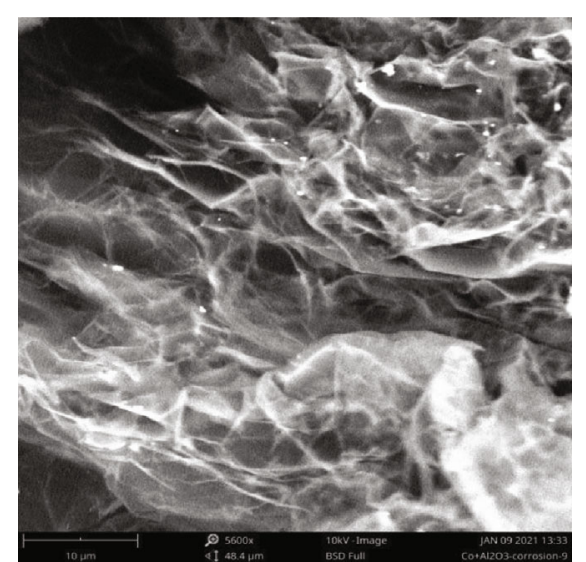

(b)

Figure 3: SEM of (a) EG and (b) LA-MA/EG composite PCMs.

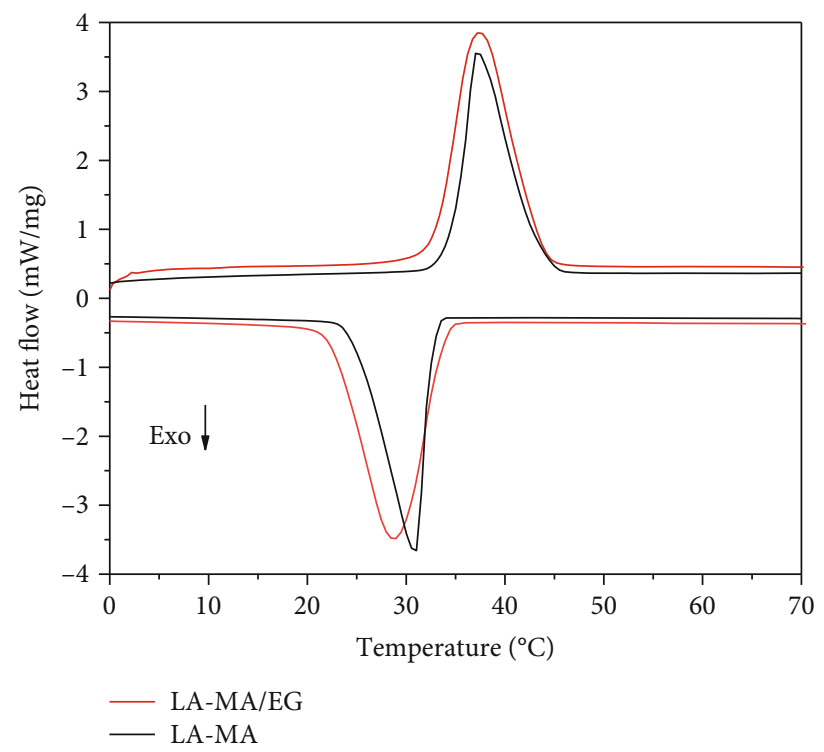

Figure 4: The DSC graphs of LA-MA PCM and LA-MA/EG CPCM.

TABLE 2: Heat performances of LA-MA PCM and LA-MA/EG CPCM.

\begin{tabular}{|c|c|c|c|c|c|c|}
\hline \multirow[b]{2}{*}{ PCM } & \multicolumn{3}{|c|}{ Melting } & \multicolumn{3}{|c|}{ Freezing } \\
\hline & $\begin{array}{l}\text { Onset temperature } \\
\qquad\left({ }^{\circ} \mathrm{C}\right)\end{array}$ & $\begin{array}{c}\text { Peak temperature } \\
\left({ }^{\circ} \mathrm{C}\right)\end{array}$ & $\begin{array}{l}\text { Latent heat } \\
\qquad(\mathrm{kJ} / \mathrm{kg})\end{array}$ & $\begin{array}{l}\text { Onset temperature } \\
\qquad\left({ }^{\circ} \mathrm{C}\right)\end{array}$ & $\begin{array}{c}\text { Peak temperature } \\
\left({ }^{\circ} \mathrm{C}\right)\end{array}$ & $\begin{array}{l}\text { Latent heat } \\
(\mathrm{kJ} / \mathrm{kg})\end{array}$ \\
\hline LA-MA & 33.9 & 37.2 & 176.9 & 32.6 & 29.8 & 154.1 \\
\hline $\begin{array}{l}\text { LA- } \\
\text { MA/EG }\end{array}$ & 33.4 & 37.4 & 171.1 & 33.8 & 28.7 & 152.3 \\
\hline
\end{tabular}

brush off the sample, and observe the filter paper permeability, and the results were displayed in Figures 1(a) and 1(b). From Figure 1(a), there were no obvious traces of leakage around the materials of the six groups of samples. After brushing away the samples, observe (Figure 1(b)) that the samples with $94 \%$ and $95 \%$ LA-MA mass content were completely permeated around the material, which did not meet the conditions of preparation of the best ratio of com- posite PCMs. The leakage of 90\%, 91\%, 92\%, and 93\% samples was not obvious, but compared with other samples, both of the samples with $90 \%$ LA-MA mass content and 91\% were dryness, pointed out that the proportion of LAMA in LA-MA/EG was too small, and the latent heat of phase change materials was too low, which does not meet the essential condition of PCM. The sample with $92 \%$ LAMA mass content had no leakage, and the sample with $93 \%$ 


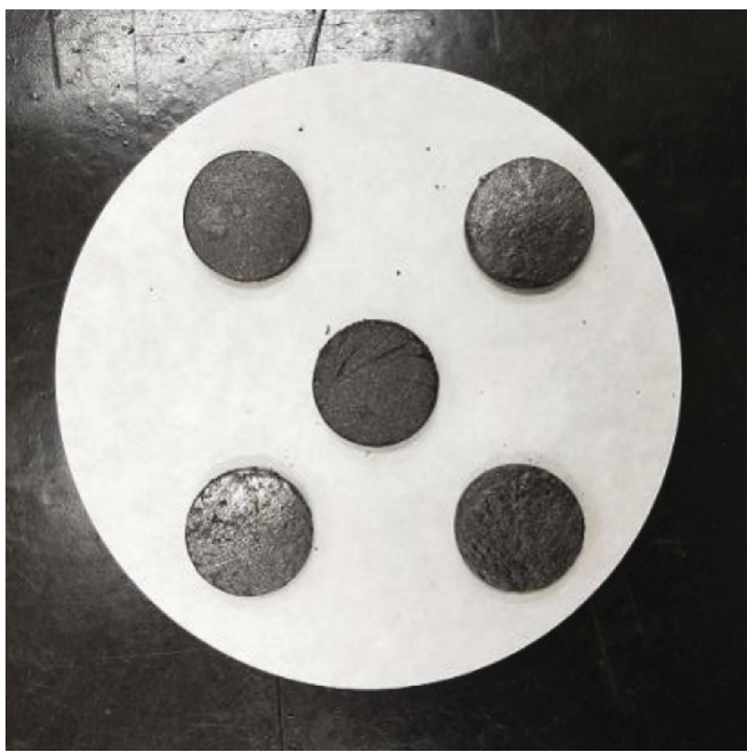

FIGURE 5: LA-MA/EG CPCM cylinder block with different stacking densities.

TABLE 3: Parameter of LA-MA/EG CPCMs with different stacking densities.

\begin{tabular}{lccccc}
\hline PCM & Mass $(\mathrm{g})$ & Thickness $(\mathrm{mm})$ & Surface area $\left(\mathrm{mm}^{2}\right)$ & Density $\left(\mathrm{kg} \cdot \mathrm{m}^{3}\right)$ & Thermal conductivity $(\mathrm{W} / \mathrm{m} \cdot \mathrm{K})$ \\
\hline PCM 1 & 1.9923 & 4.7 & 707 & 600.00 & 4.225 \\
PCM 2 & 1.7336 & 4.8 & 707 & 510.84 & 4.293 \\
PCM 3 & 1.1888 & 4.5 & 707 & 373.92 & 2.135 \\
PCM 4 & 1.7633 & 5.1 & 707 & 489.38 & 3.430 \\
PCM 5 & 1.3219 & 4.6 & 707 & 406.75 & 2.982 \\
\hline
\end{tabular}

LA-MA mass content had some samples adsorbed in the test area, evidenced that the optimal ratio was approximate $92 \%-$ 93\%. The previous experimental steps were repeated and observed. The experimental results were displayed in Figures 1(c) and 1(d). From Figure 1(c), for further identifying the maximum mass ratio, four groups of LA-MA/EG composite PCM samples with $92.2 \%, 92.4 \%, 92.6 \%$, and 92.8\% LA-MA content were prepared again, and there were no leakages of the binary eutectic mixture solution around the samples. After brushing off the samples, it was observed in Figure 1(d) that the LA-MA mass content of $92.4 \%$, $92.6 \%$, and $92.8 \%$ of the samples remained on the filter paper to varying degrees, while the sample with $92.2 \%$ LA-MA mass content of the filter paper had no adsorption. Therefore, the maximum mass ratio of the binary eutectic mixture in LA-MA/EG was $92.2 \%$.

3.2. FTIR Analysis of the LA-MA/EG Composite PCMs. Fourier transform infrared spectrometer was used to characterize the chemical construction of the LA-MA binary eutectic mixture and LA-MA/EG. As shown in Figure 2, the absorption peak of $\mathrm{C}=\mathrm{O}$ stretching vibration appeared in both the two spectral curves at $1689 \mathrm{~cm}^{-1}$, and the absorption peak in the wavenumber range of $2960-2840 \mathrm{~cm}^{-1}$ was the stretching vibration absorption peak of hydroxyl O-H, which usually overlaps with $\mathrm{C}-\mathrm{H}$ stretching vibration absorption

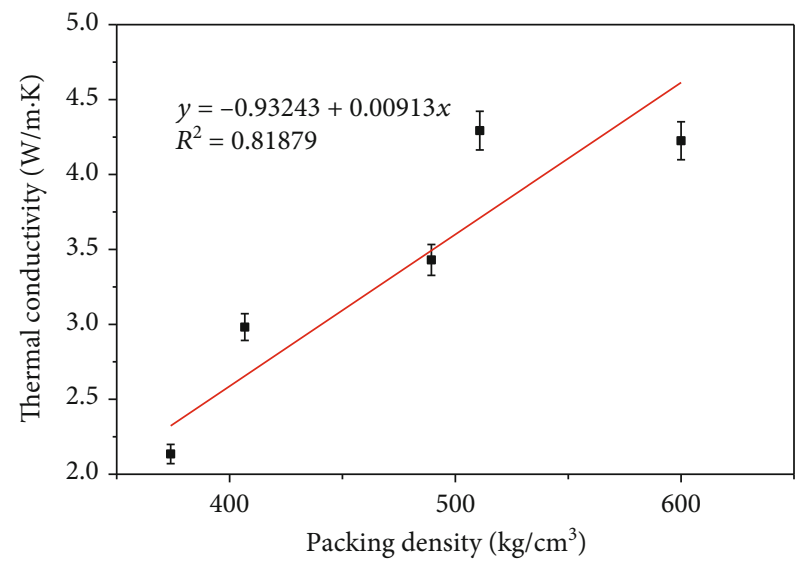

FIgURE 6: Thermal conductivities change with different stacking densities of LA-MA/EG CPCMs.

peaks of the aliphatic group. It can be seen from Figure 2 that the spectral curves of LA-MA and LA-MA/EG were basically the same, and the position of the characteristic peaks corresponded to one. The results indicated that after adding EG, the LA-MA/EG composite PCMs did not produce new material and had no change in the structure. Between the LA-MA and EG, there was no chemical equation and depends on surface tension and capillary force. 


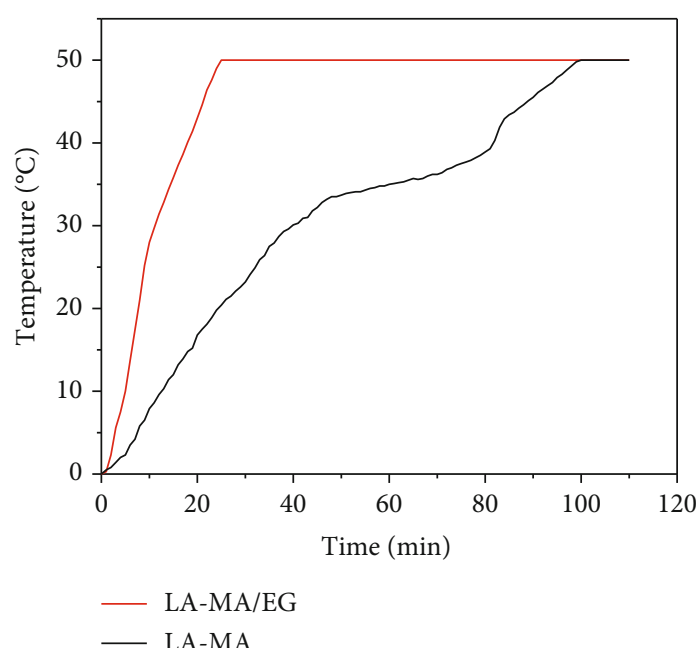

(a)

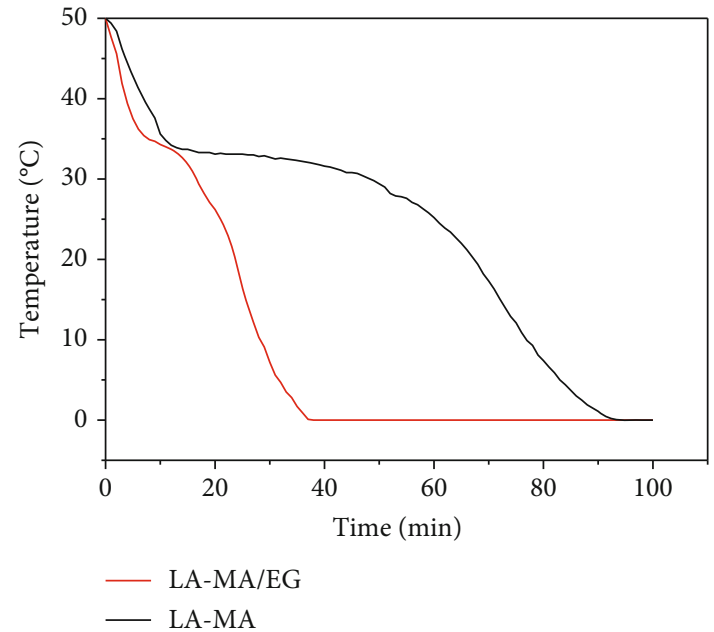

(b)

Figure 7: The curves of LA-MA PCM and LA-MA/EG CPCM (a) storage and (b) release heat.

3.3. Microstructure of the LA-MA/EG Composite PCMs. EG and LA-MA/EG composite PCM microstructure diagrams were shown in Figures 3(a) and 3(b), respectively, by SEM. According to Figure 3(a), EG was a network pore structure material, composed with graphite flake and plenty of irregular pores, and the stronger surface tension makes EG adsorb the LA-MA binary eutectic mixture much better. From Figure 3(b), it indicated that the LA-MA has been evenly absorbed in the pore structure of EG. The pores were filled with solution and not easy to leak. The results show that EG has a good adsorption effect, can provide a certain mechanical strength, and prevent leakage as a matrix material.

3.4. Thermal Properties of the LA-MA/EG Composite PCMs. The thermal performance of phase change energy storage materials was measured by DSC; Figure 4 shows the DSC curves of LA-MA and LA-MA/EG, and the thermal performance is shown in Table 2.

Table 2 displays that the fusing point temperature of the LA-MA was $33.9^{\circ} \mathrm{C}$, the melting latent thermal was $176.9 \mathrm{~J} / \mathrm{g}$, the solidification point temperature was $32.6^{\circ} \mathrm{C}$, and the freezing latent thermal was $154.1 \mathrm{~J} / \mathrm{g}$. The molten temperature point of $\mathrm{LA}-\mathrm{MA} / \mathrm{EG}$ was $33.4^{\circ} \mathrm{C}$, the melting latent heat was $171.1 \mathrm{~J} / \mathrm{g}$, the freezing temperature point was $33.8^{\circ} \mathrm{C}$, and the freezing latent thermal was $152.3 \mathrm{~J} / \mathrm{g}$. By comparison, the melting temperature of LA-MA/EG was marginally lesser than LA-MA, but the solidification temperature was a bit higher than LA-MA, which due to the addition of EG, it enhances the thermal conductivity of the prepared composite PCMs. The high thermoconductivity of the matrix material increases the heat transfer rate of PCMs [44] and leads to a lower phase transition temperature.

3.5. Thermal Conductivity and Heat Storage/Release Behavior of $L A-M A / E G$ Composite PCM. In order to test the relationship between the coefficient of thermal conductivity and different densities of LA-MA/EG composite phase change

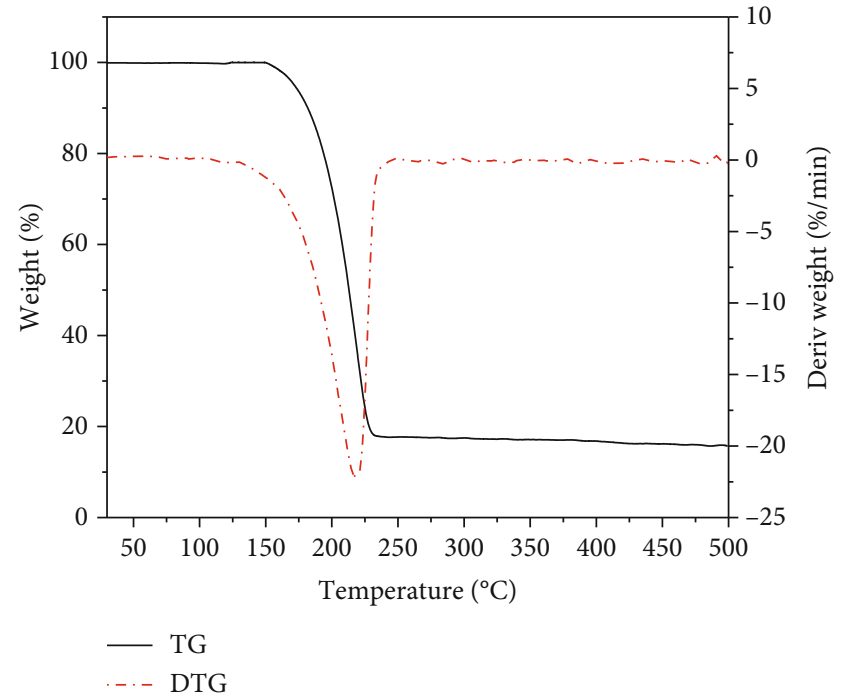

FIgURE 8: TG and DTG curves of LA-MA/EG CPCMs.

materials at different bulk densities, in this experiment, 5 cakes of different weights were prepared by using a $3 \times 3 \mathrm{~cm}$ cake membrane (shown in Figure 5), and then, their thermal conductivity was measured, and the results were displayed in Table 3 and Figure 6 . When the packing density of PCMs was $600.00 \mathrm{~kg} / \mathrm{m}^{3}, 510.84 \mathrm{~kg} / \mathrm{m}^{3}, 373.93 \mathrm{~kg} / \mathrm{m}^{3}, 489.38 \mathrm{~kg} / \mathrm{m}^{3}$, and $406.75 \mathrm{~kg} / \mathrm{m}^{3}$, respectively, the thermal conductivity of PCMs was $\quad 4.225 \mathrm{~W} / \mathrm{m} \cdot \mathrm{K}, \quad 4.293 \mathrm{~W} / \mathrm{m} \cdot \mathrm{K}, \quad 2.135 \mathrm{~W} / \mathrm{m} \cdot \mathrm{K}, \quad 3.430$ $\mathrm{W} / \mathrm{m} \cdot \mathrm{K}$, and $2.982 \mathrm{~W} / \mathrm{m} \cdot \mathrm{K}$, respectively. At the sample density between 373.93 and $600.00 \mathrm{~kg} / \mathrm{m}^{3}$, the relationship between the packing density $x\left(\mathrm{~kg} \cdot \mathrm{m}^{3}\right)$ of LA-MA/EG and the thermoconductivity $y(\mathrm{~W} / \mathrm{m} \cdot \mathrm{K})$ was linear through fitting analysis. Formula (1) was obtained by fitting the data in Table 3.

$$
y=0.00913 x-0.93243\left(R^{2}=0.81879\right) .
$$




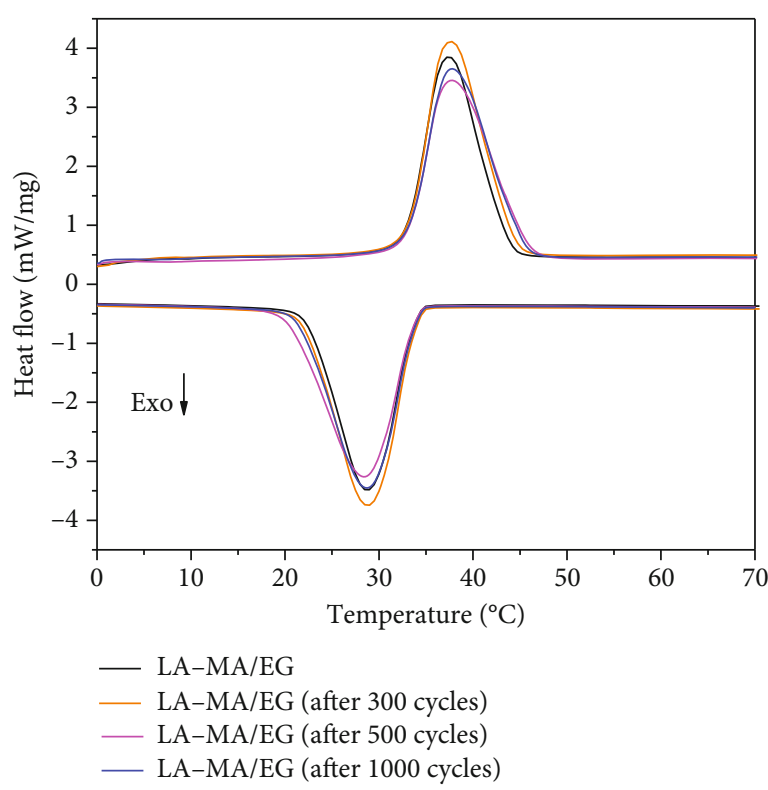

(a)

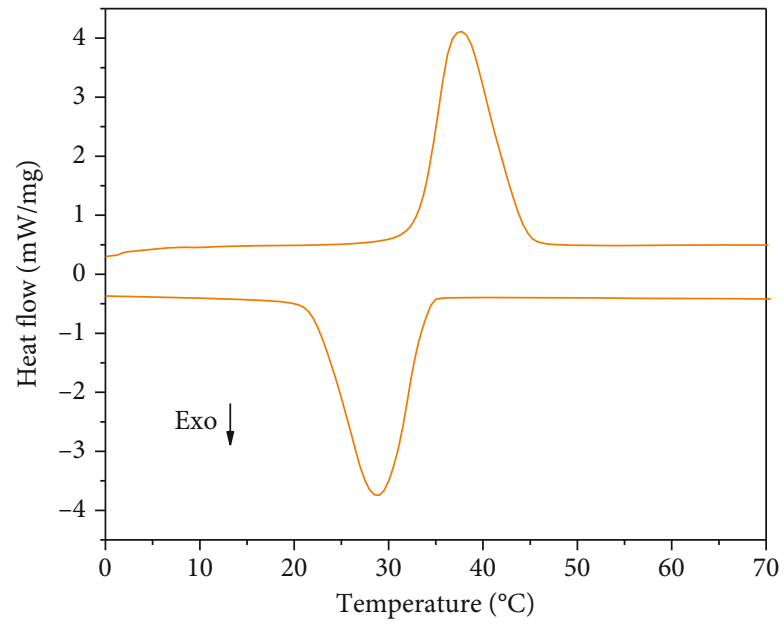

_ LA-MA/EG (after 300 cycles)

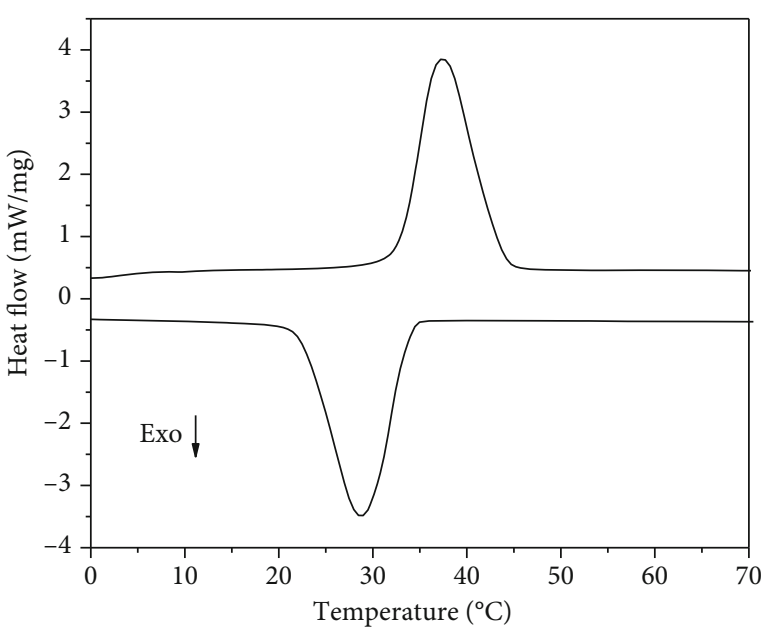

— LA-MA/EG (b)

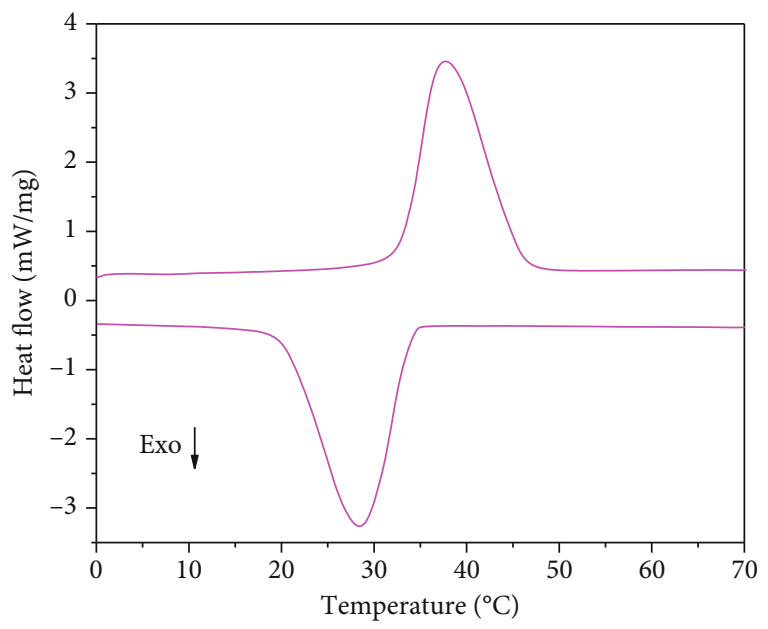

— LA-MA/EG (after 500 cycles)

(d)

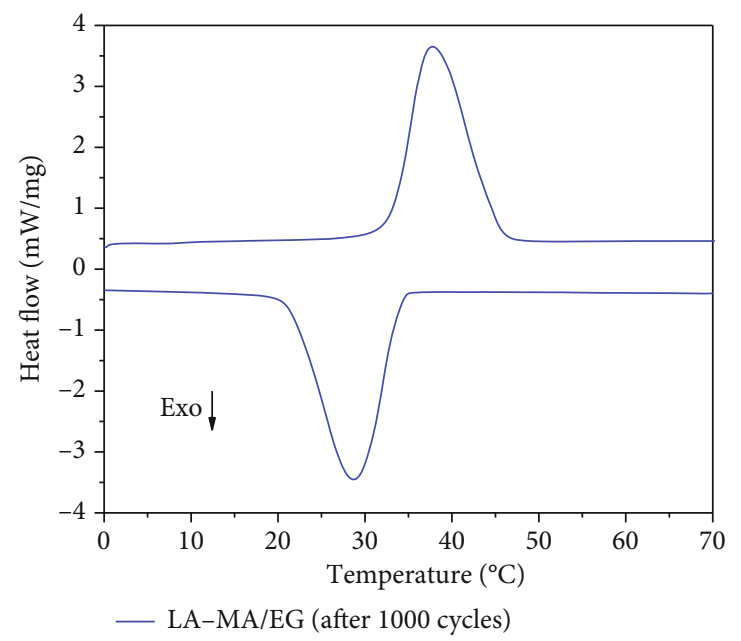

(e)

FIgURE 9: The DSC curves of LA-MA/EG CPCMs before and after thermal cycling. 
The temperature probes were placed into the center of the beaker with the same volume of LA-MA and LA$\mathrm{MA} / \mathrm{EG}$, respectively. Then, the beakers were put into the same constant temperature environment, and when the temperature of the materials were stable and reached the set value, begin the test. The temperature setting of the exothermic process was $0^{\circ} \mathrm{C}$, and the endothermic process temperature was set as $50^{\circ} \mathrm{C}$; the test results are shown in Figure 7. The heat absorption curves of the binary fatty acid and the composite PCM were shown in Figure 7(a), and it was obvious that LA-MA/EG composite PCM takes lesser time to reach the set temperature than LA-MA. The time required for $\mathrm{LA}-\mathrm{MA} / \mathrm{EG}$ heating from $0^{\circ} \mathrm{C}$ to $50^{\circ} \mathrm{C}$ was $25 \mathrm{~min}$, while the heating of LA-MA to $50^{\circ} \mathrm{C}$ was taken $100 \mathrm{~min}$. Figure 7(b) shows the exothermic curve. It only spent 37 min for the exothermic cooling of LA-MA/EG to reach $0^{\circ} \mathrm{C}$, while the time required for the exothermic cooling of $\mathrm{LA}-\mathrm{MA}$ to reach $0^{\circ} \mathrm{C}$ was $93 \mathrm{~min}$. The results suggested that the thermoconductivity of LA-MA/EG was significantly improved compared with that of LA-MA, indicating that the multipore structure of EG optimized the thermoconductivity of the composite PCMs [45].

3.6. Thermal Stability and Reliability of $L A-M A / E G$ Composite PCM. In terms of phase change materials, whether they still have good thermal stability and no volatilization after thermal cycles, which was to judge whether it can be applied in building energy efficiency standards, in this experiment, the thermal stability of LA-MA/EG was tested by thermogravimetry, and the sample test temperature was set from room temperature to $500^{\circ} \mathrm{C}$ which heated in a nitrogen atmosphere. The curves are shown in Figure 8. The LAMA/EG composite phase change material begins to be weightless at the temperature of $150^{\circ} \mathrm{C}$, and the residual quality of TG was $15.75 \%$. After the first-order differential of the TG curve, it can be obtained that the maximum weight loss rate of LA-MA/EG reached $22.44 \% / \mathrm{min}$ when the temperature was $219^{\circ} \mathrm{C}$. The results have shown that at temperatures lower than $150^{\circ} \mathrm{C}$, even if the fusion temperature of LA-MA was above, the LA-MA in LA-MA/EG would be protected from evaporation. Therefore, LA-MA/EG composite PCM has a capable thermostability in low-temperature utilization.

Thermal reliability is one of the important performance indexes to measure the service life of the CPCMs [46]. In order to test whether the LA-MA/EG still has favorable thermal stability and reliability after multiple thermocyclings, perform the DSC measurement of CPCMs after 300, 500, and 1000 thermal cycles. The DSC curves and heat performance were shown in Figure 9 and Table 4. From Figure 9, after 300, 500, and 1000 thermal cycles, the fusion temperatures of LA-MA/EG composite PCMs were $33.2^{\circ} \mathrm{C}, 33.0^{\circ} \mathrm{C}$, and $33.1^{\circ} \mathrm{C}$, and the freezing temperature of CPCM was $34.0^{\circ} \mathrm{C}, 33.8^{\circ} \mathrm{C}$, and $33.9^{\circ} \mathrm{C}$, separately. The latent heat of fusion and solidification of LA-MA/EG composite phase change material before cycling was decreased by $3.04 \%$, $1.05 \%, 4.9 \%, 2.37 \%, 6.8 \%$, and $3.21 \%$, respectively. The phase transition temperature and latent heat of LA-MA/EG composite PCMs were obvious, which indicates that the CPCM has good thermal stability and reliability.
TABLE 4: Heat performances of LA-MA/EG CPCM.

\begin{tabular}{lcccc}
\hline $\begin{array}{l}\text { Number } \\
\text { of thermal } \\
\text { cycling }\end{array}$ & $\begin{array}{c}\text { Melting } \\
\text { temperatures } \\
\left({ }^{\circ} \mathrm{C}\right)\end{array}$ & $\begin{array}{c}\text { Melting } \\
\text { latent heat } \\
(\mathrm{kJ} / \mathrm{kg})\end{array}$ & $\begin{array}{c}\text { Freezing } \\
\text { temperatures } \\
\left({ }^{\circ} \mathrm{C}\right)\end{array}$ & $\begin{array}{c}\text { Freezing } \\
\text { latent heat } \\
(\mathrm{kJ} / \mathrm{kg})\end{array}$ \\
\hline 0 & 33.4 & 171.1 & 33.8 & 152.3 \\
300 & 33.2 & 165.9 & 34.0 & 150.7 \\
500 & 33.0 & 162.7 & 33.8 & 148.7 \\
1000 & 33.1 & 159.4 & 33.9 & 147.4 \\
\hline
\end{tabular}

\section{Conclusion}

In this paper, the LA-MA binary eutectic mixture as PCM and EG as adsorption material, an LA-MA/EG composite PCM was prepared by physical adsorption method, and its thermal properties were characterized. The results showed that the mixture between the LA-MA and EG was physically blended without chemical reaction. The best mass ratio of LA-MA in LA-MA/EG was $92.2 \%$. The phase transition temperature and potential heat of LA-MA/EG composite phase change materials were $33.4^{\circ} \mathrm{C}$ and $171.1 \mathrm{~J} / \mathrm{g}$, individually. The thermal cycling experiment shows that the thermal properties of LA-MA/EG composite phase change energy storage material would not change greatly after several thermal cycles, which displayed that the composite PCM has excellent thermal reliability. The thermoconductivity of LA-MA/EG was surveyed, which showed that the thermal conductivity of the PCMs was greatly improved due to the porous structure of EG, and the energy storage and release rate of LA-MA/EG were greatly improved. The TG experiment shows that LA-MA/EG has good thermal stability. In conclusion, as a composite PCM with remarkable performance, LA-MA/EG can be extensively used in lowtemperature energy storage areas, for instance, solar energy utilization, condenser heat recovery in the household air conditioning, and energy efficiency in building.

\section{Data Availability}

The data availability of the manuscript can be found at https://figshare.com/s/8e0057712bcda7642808.

\section{Conflicts of Interest}

The authors declare that there are no conflicts of interest.

\section{Acknowledgments}

This research was funded by the Key R and D Project of Hunan Provincial (Grant No. 2018GK2074).

\section{References}

[1] A. Sar1 and A. Karaipekli, "Preparation, thermal properties and thermal reliability of palmitic acid/expanded graphite composite as form-stable PCM for thermal energy storage," Solar Energy Materials \& Solar Cells, vol. 93, no. 5, pp. 571576, 2009. 
[2] A. F. Regin, S. C. Solanki, and J. S. Saini, "Heat transfer characteristics of thermal energy storage system using PCM capsules: a review," Renewable and Sustainable Energy Reviews, vol. 12, no. 9, pp. 2438-2458, 2008.

[3] C. Liu, Y. Song, Z. Xu, J. Zhao, and Z. Rao, "Highly efficient thermal energy storage enabled by a hierarchical structured hypercrosslinked polymer/expanded graphite composite," International Journal of Heat and Mass Transfer, vol. 148, p. 119068, 2019.

[4] T. X. Li, J. H. Lee, R. Z. Wang, and Y. T. Kang, "Enhancement of heat transfer for thermal energy storage application using stearic acid nanocomposite with multi-walled carbon nanotubes," Energy, vol. 55, pp. 752-761, 2013.

[5] Sheikholeslami and Mohsen, "Numerical simulation for solidification in a LHTESS by means of nano-enhanced PCM," Journal of the Taiwan Institute of Chemical Engineers, vol. 86, pp. 25-41, 2018.

[6] Y. Yuan, Y. Yuan, N. Zhang, Y. du, and X. Cao, "Preparation and thermal characterization of capric-myristic-palmitic acid/expanded graphite composite as phase change material for energy storage," Materials Letters, vol. 125, pp. 154-157, 2014.

[7] H. Fei, L. Wang, Q. He, W. du, Q. Gu, and Y. Pan, "Preparation and properties of a composite phase change energy storage gypsum board based on capric acid-paraffin/expanded graphite," ACS Omega, vol. 6, no. 9, pp. 6144-6152, 2021.

[8] C. Liu, Y. Yuan, N. Zhang, X. Cao, and X. Yang, "A novel PCM of lauric-myristic-stearic acid/expanded graphite composite for thermal energy storage," Materials Letters, vol. 120, pp. 43-46, 2014.

[9] B. Yang, J. Liu, Y. Song, N. Wang, and H. Li, "Experimental study on the influence of preparation parameters on strengthening stability of phase change materials (PCMs)," Renewable Energy, vol. 146, pp. 1867-1878, 2020.

[10] M. Pomianowski, P. Heiselberg, and Y. Zhang, "Review of thermal energy storage technologies based on PCM application in buildings," Energy and Buildings, vol. 67, pp. 56-69, 2013.

[11] F. L. Liu, J. Q. Zhu, J. H. Liu, B. Ma, W. Zhou, and R. Li, "Preparation and properties of capric-stearic acid/White Carbon Black composite for thermal storage in building envelope," Energy and Buildings, vol. 158, pp. 1781-1789, 2018.

[12] D. Aydin, S. P. Casey, and S. Riffat, "The latest advancements on thermochemical heat storage systems," Renewable and Sustainable Energy Reviews, vol. 41, pp. 356-367, 2015.

[13] A. Shukla, D. Buddhi, and R. L. Sawhney, "Solar water heaters with phase change material thermal energy storage medium: a review," Renewable and Sustainable Energy Reviews, vol. 13, no. 8, pp. 2119-2125, 2009.

[14] R. Elarem, T. Alqahtani, S. Mellouli et al., "Numerical study of an Evacuated Tube Solar Collector incorporating a NanoPCM as a latent heat storage system," Case Studies in Thermal Engineering, vol. 24, p. 100859, 2021.

[15] G. Y. Fang, T. Fang, and L. Cao, "Preparation, thermal properties and applications of shape-stabilized thermal energy storage materials," Renewable and Sustainable Energy Reviews, vol. 40, pp. 237-259, 2014.

[16] B. Gin and M. M. Farid, "The use of PCM panels to improve storage condition of frozen food," Journal of Food Engineering, vol. 100, no. 2, pp. 372-376, 2010.

[17] H. Fei, W. du, Q. J. Gu, L. Wang, Q. He, and Y. Pan, "The Phase Change Characteristics of Capric Acid-based Binary Low Eutectic Mixtures Adsorbed in Expanded Graphite," Energy and Fuels, vol. 34, no. 11, pp. 14893-14901, 2020.
[18] Q. H. Yu, F. Tchuenbou-Magaia, B. al-Duri, Z. Zhang, Y. Ding, and Y. Li, "Thermo-mechanical analysis of microcapsules containing phase change materials for cold storage," Applied Energy, vol. 211, pp. 1190-1202, 2018.

[19] C. R. Raj, S. Suresh, V. K. Singh, R. R. Bhavsar, M. Chandrasekar, and V. Archita, "Life cycle assessment of nanoalloy enhanced layered perovskite solid-solid phase change material till 10000 thermal cycles for energy storage applications," Journal of Energy Storage, vol. 35, p. 102220, 2021.

[20] G. Y. Wang, D. S. Ha, and K. G. Wang, "A scalable environmental thermal energy harvester based on solid/liquid phasechange materials," Applied Energy, vol. 250, pp. 1468-1480, 2019.

[21] S. Riffat, "Phase change material developments: a review," International Journal of Ambient Energy, vol. 36, no. 3, pp. 102-115, 2015.

[22] A. Wang, M. W. Hu, D. K. Tao, and J. Wang, "Analysis and Application of Phase Change Materials on Energy Saving in Buildings," Advanced Materials Research, vol. 411, pp. 523526, 2011.

[23] N. Şahan and H. Paksoy, "Investigating thermal properties of using nano-tubular Zno powder in paraffin as phase change material composite for thermal energy storage," Composites Part B: Engineering, vol. 126, pp. 88-93, 2017.

[24] B. T. Tang, L. J. Wang, Y. J. Xu, J. Xiu, and S. Zhang, "Hexadecanol/phase change polyurethane composite as form-stable phase change material for thermal energy storage," Solar Energy Materials and Solar Cells, vol. 144, pp. 1-6, 2016.

[25] A. Sar, "Eutectic mixtures of some fatty acids for latent heat storage: Thermal properties and thermal reliability with respect to thermal cycling," Energy Conversion and Management, vol. 47, no. 9-10, pp. 1207-1221, 2006.

[26] L. J. Wang and D. Meng, "Fatty acid eutectic/polymethyl methacrylate composite as form-stable phase change material for thermal energy storage," Applied Energy, vol. 87, no. 8, pp. 2660-2665, 2010.

[27] S. F. Wu, T. Yan, Z. H. Kuai, and W. Pan, "Thermal conductivity enhancement on phase change materials for thermal energy storage: A review," Energy Storage Materials, vol. 25, pp. 251295, 2020.

[28] R. S. R. da Silva, S. S. Oishi, E. C. Botelho, and N. G. Ferreira, "Carbon foam composites based on expanded graphite for electrochemical application," Diamond and Related Materials, vol. 103, p. 107730, 2020.

[29] Z. G. Zhang, G. Shao, and X. M. Fang, "Study on paraffin/expanded graphite composite phase change thermal energy storage material," Energy Conversion and Management, vol. 47, no. 3, pp. 303-310, 2006.

[30] J. H. Jia and L. Zhu, "Influence of the aerogel/expanded perlite composite as thermal insulation aggregate on the cementbased materials: preparation, property, and microstructure," Construction and Building Materials, vol. 273, p. 121728, 2021.

[31] X. W. Fu, Z. M. Liu, B. Wu, J. Wang, and J. Lei, "Preparation and thermal properties of stearic acid/diatomite composites as form-stable phase change materials for thermal energy storage via direct impregnation method," Journal of Thermal Analysis and Calorimetry, vol. 123, no. 2, pp. 1173-1181, 2016.

[32] T. Y. Wang, S. F. Wang, R. L. Luo, C. Zhu, T. Akiyama, and Z. Zhang, "Microencapsulation of phase change materials with binary cores and calcium carbonate shell for thermal energy storage," Applied Energy, vol. 171, pp. 113-119, 2016. 
[33] Y. P. Wu and T. Wang, "Preparation and characterization of hydrated salts/silica composite as shape- stabilized phase change material via sol-gel process," Thermochimica Acta, vol. 591, pp. 10-15, 2014.

[34] A. Sar, A. Karaipekli, and C. Alkan, "Preparation, characterization and thermal properties of lauric acid/expanded perlite as novel form-stable composite phase change material," Chemical Engineering Journal, vol. 155, no. 3, pp. 899-904, 2009.

[35] H. Zhang, X. Gao, C. Chen, T. Xu, Y. Fang, and Z. Zhang, “A capric-palmitic-stearic acid ternary eutectic mixture/expanded graphite composite phase change material for thermal energy storage," Composites Part A: Applied Science and Manufacturing, vol. 87, pp. 138-145, 2016.

[36] D. Y. Zhou, J. W. Yuan, Y. H. Zhou, and Y. Liu, "Preparation and Properties of Capric-Myristic Acid/Expanded Graphite Composite Phase Change Materials for Latent Heat Thermal Energy Storage," Energies, vol. 13, no. 10, p. 2462, 2020.

[37] X. Huang, Y. D. Cui, B. N. Zhang, G. Q. Yin, and G. Z. Feng, "Preparation and Properties of Capric-Lauric-Palmitic Acid Eutectic Mixtures/Expanded Graphite Composite as Phase Change Materials for Energy Storage," Advanced Materials Research, vol. 1028, pp. 40-45, 2014.

[38] J. F. Luo, H. W. Yin, W. Y. Li et al., "Numerical and experimental study on the heat transfer properties of the composite paraffin/expanded graphite phase change material," International Journal of Heat and Mass Transfer, vol. 84, pp. 237244, 2015.

[39] D. Zhou, Y. Zhou, J. Yuan, and Y. Liu, "Palmitic Acid-Stearic Acid/Expanded Graphite as Form-Stable Composite PhaseChange Material for Latent Heat Thermal Energy Storage," Journal of Nanomaterials, vol. 2020, 9 pages, 2020.

[40] X. Yang, Y. Yuan, N. Zhang, X. Cao, and C. Liu, "Preparation and properties of myristic-palmitic-stearic acid/expanded graphite composites as phase change materials for energy storage," Solar Energy, vol. 99, pp. 259-266, 2014.

[41] Y. Yuan, Y. Yuan, N. Zhang, Y. du, and X. Cao, "Preparation and thermal characterization of capric-myristic-palmitic acid/expanded graphite composite as phase change material for energy storage," Materials Letters, vol. 125, no. 1, pp. 154-157, 2014.

[42] H. Zhu, P. Zhang, Z. Meng, and M. Li, “Thermal Characterization of Lauric-Stearic Acid/Expanded Graphite Eutectic Mixture as Phase Change Materials," Journal of Nanoscience and Nanotechnology, vol. 15, no. 4, pp. 3288-3294, 2015.

[43] Y. Wang, H. Zheng, H. X. Feng, and D. Y. Zhang, "Effect of preparation methods on the structure and thermal properties of stearic acid/activated montmorillonite phase change materials," Energy and Buildings, vol. 47, pp. 467-473, 2012.

[44] M. Li and J. Shi, "Review on micropore grade inorganic porous medium based form stable composite phase change materials: preparation, performance improvement and effects on the properties of cement mortar," Construction and Building Materials, vol. 194, pp. 287-310, 2019.

[45] R. A. Mahdi, H. A. Mohammed, K. M. Munisamy, and N. H. Saeid, "Review of convection heat transfer and fluid flow in porous media with nanofluid," Renewable \& Sustainable Energy Reviews, vol. 41, pp. 715-734, 2015.

[46] Q. Y. Yan, C. Liu, J. Zhang, S. Liu, and X. Sun, "Research on proportion and thermal storage property of the shape stabilized fatty acid," Journal of Physics Conference Series, vol. 1074, no. 1, p. 012156, 2018. 